\title{
Research on the Pastoral Landscape Design of the Aged Community under the Public Space
}

\author{
Yuansheng Huang and Yousheng Li \\ Nanchang Hangkong University, Nanchang, Jiangxi, China
}

\begin{abstract}
Aims: This paper focuses on the applied research of idyllic landscape design in the public space of the elderly community and seeks to build a rustic, natural and ecological environment for the aged. Methods: Through literature review, with inductive method and crossover research method, the pastoral landscape design in the elderly community public space was comprehensively studied. Conclusion: The evolution of pastoral ideological theory is analyzed, and the significance of idyllic landscape design in the public space of the elderly community is summarized, and the related design principles and conceptions are put forward.
\end{abstract}

Keywords-elderly community; public space; pastoral landscape design; elderly

China Social Science Network Data Center released the result of the fourth sampling survey of living conditions of urban and rural elderly in China on 10 October, 2016. The data show that the total number of disabled and partially disabled elderly in China counts to 40.63 million and accounted for $18.3 \%$ of the total population of the elderly, of which urban areas $79.2 \%$ of elderly people live in old buildings without elevators. ${ }^{[1]}$ From the data point of view, neither living space nor public space can be provided to the elderly as rustic, natural, ecological pension environment. In recent years, the intensification of aging has added up to a sudden increase of disabled seniors and the pension situation is under greater pressure, but few paper composers have studied the application of rural landscape design in the public space of the elderly community. Therefore, under that background, the study of rural landscape design in the public space of the elderly community has a positive effect on improving the health and retirement environment for the elderly.

\section{The Evolution OF PAStORAL THEORY}

\section{A. Howard's Garden City Concept}

Howard's idylls design concept is the first idea in such themes, firstly came into being in 1898 under the situation that in London, the population grew from 1.1 million to 6.5 million, and social problems emerged such as employment and housing. The most famous theory of it is the theory of three magnets, pointing out that the combination of urban and rural like magnets, that is, combining the advantages of pastoral and natural beauty in rural areas with employment, residence and opportunities in urban areas, taking its essence and discarding its dross. City magnet integration refers to the establishment of a pastoral city, whose population, area, function have a detailed planning. The pastoral city is the imagination of the forefathers' pastoral work, surrounded by the green belt. The standard of the world's first proposed pastoral design is to meet the work, health, psychological needs. It is also an important theoretical source and support of this article.

\section{B. McHarg's Design Combines Nature}

Ian McHaugger was born in Glasgow in 1920 when Glasgow was a heavily industrialized city, and McHugh's childhood experience of rural life was fantastic: farmland, hawthorn, cows, horses, and lakes and stream water. Having this experience, 16-year-old Machagat, wanted to make his landscape ecology project a lifelong undertaking in 1935, as demonstrated by the first American publication "Design with Nature" in 1967.The book combines multidisciplinary ideas such as ecology, geography, culture, environment and other disciplines, and studies on the cross between ocean, green space, climate, ecology, vegetation and rural cities, which provide the theoretical basis for modern landscape design. Therefore, the design idea of "combining design with nature" can provide the basis of thoughts for the pastoral landscape design of public space in the elderly community.

\section{Qian Xuesen's Landscape Design Ideas}

The Spring and Autumn Period and the Warring States Period are the beginning stages of landscape thought: Confucius put forward the thought of "joy of landscape"; Taoist Laozi and Zhuangzi's "Inaction" and "Taoism and nature". These thoughts originated from the cognition of natural landscape. The thought of landscape was developed in the Qin and Han dynasties. The emperor Qin Shihuang found his inspiration from the mythology of Penglai and created a design idea of one pool plus three mountains. When the literati were frustrated in life, or retreated to remote mountains, or indulgent in rivers and lakes, Fond in Mountain and River became a kind of culture. In the Wei, Jin, Southern and Northern Dynasties, the thoughts of landscapes, artistic conceptions and natural beauty were developed to the peak. For example, Tao Yuanming's "Peach Blossom Spring" narrates the beauty of the pastoral landscape and expresses the yearning for natural poetic life.

In the 20th century, the design principle of "less is more", which Meis van der Roe put forward, has affected two-thirds of the world's city skyline. The chase of the modernist design philosophy has also led to the gradual emergence of the phenomenon of "one type of a thousand city" in China. In the face of the loss of traditional landscape culture, Qian Xuesen, who was deeply influenced by western design thoughts, mailed in July 1990 to $\mathrm{Mr}$. Wu Lianglian of Tsinghua University with the concept of landscape city: integrating Chinese landscape idea with modern design. The idea is to 
restore the national consciousness of the landscape pastoral ideology and to apply the traditional ideas of landscape culture, landscapes and natural beauty to urban planning, landscapes, gardens and interior design. This not only reflects the history of pastoral landscapes in China design, but also for follow-up study with basis, reference and guidance.

\section{THE SIGNIFICANCE OF CONSTRUCTING PASTORAL LANDSCAPE DESIGN IN OLD COMMUNITY PUBLIC SPACE}

China's main provide for elderly has been the home-based one, but in recent years, pastoral style becomes a new model. In actual operation, the pastoral community public space garden landscape is an important component of pastoral care, so it is necessary to explore its meaning.

\section{A. Enhance the Visual and Emotional Experience of the Elderly}

Immature flowers, simple pastoral, quiet lake, towering green forest, changing rockery, ink stone and other scenery and architecture, settlements, cottages, ancient trees and other scenes : full of memory of childhood native life. Lively and vivid real sense of the picture, touched the elderly's lonely weak inner most. The idyllic landscape has the functions of complete functions, harmonious landscape, high greening rate and peaceful and serene aged environment, which can create an elegant environment and high-quality landscape visual experience for the elderly to be close to nature.

\section{B. Benefit to the Elderly's Physical and Mental Health}

With the growth of the elderly, the physical and sensory functions of the elderly are deteriorating, and the decline of physical strength, the decline of the visual, the taste, the hearing, the sense of touch and the decrease of the sensitivity of smell are prone to occur, which also plagued the daily life of the elderly. At the same time, the lack of relatives can easily make the elderly feel lonely, pessimistic and other negative emotions. In view of the physiological and behavioral characteristics of the elderly, we design green and secure pastoral workplaces so that the seniors get the physical and spiritual satisfaction through the cultivation of flowers, seeds, sowing, watering and weeding. More than that, creating an idyllic landscape of pastoralism in the public spaces of the elderly community can bring a kind of "soothing" psychological comfort to the elderly through the beautiful scenery. Therefore, excellent rural landscape design benefits the physical and mental health of the elderly.

\section{Carry Forward the Traditional Design Concept}

Chinese traditional garden design is profound: landscape construction combines the nature and poetry together, and it is unique in the history of world gardens. The application of traditional design ideas in the design and construction of elderly community public spaces not only conforms to the peaceful and harmonious state of psychology of the elderly, enabling them to enjoy all the time, but also tends to be permeated with Chinese traditional philosophy, unique aesthetic taste and beautiful nature Landscape and Landscape Humanism Inherit.In this process of integration, history, reality, tradition and modernity, the eastern and western thoughts collide, blend, absorb each other and embrace each other, creating new ideas and designing concepts and ideas. All of that makes a big contribution to the world.

\section{Beneficial to Build Ecological, Natural Landscape}

The idyllic landscape of the elderly community public space is composed of landscapes such as picturesque landscape, green forest landscape, agricultural landscape and rural settlements, and has the characteristics of green ecology. The idyllic landscape can not only silence the noise and create a quiet living environment, but also improve the air quality in the community by improving the local microclimate. In the design, pastoral landscape through the use of the ups and downs of the terrain, the meandering river, the mountains and green artificial landscape is mixed with natural landscape, sketching out a harmonious coexistence of man and nature picture. The image is an idyllic view of the public space of a contemporary anonymous community that is harmoniously mixed with elements such as farmland, vegetable fields, orchards, hillsides, wells, wooden bridges and clusters. This concept of landscape design is in line with the traditional Chinese idea of harmony between man and nature and is of great guiding significance to the construction of ecological and natural pastoral landscapes by integrating modern green design concepts.

\section{The DESIGN PRINCIPLES OF RURAL LANDSCAPE IN THE ELDERLY COMMUNITY PUBLIC SPACE}

\section{A. Design Principles of Humanistic Beauty}

The design principles of humane beauty include design principles of people-oriented and cultural significance. People-oriented design principles is the elderly being centered, in the design reflecting the importance of the safety of the elderly. Due to the poor physical condition of the elderly, safety in amusement and workmanship is often the primary consideration. The safety of play and simple labor needs to be ensured through proper planning. For example, locomotive classification should be applied to traffic planning to establish a barrier-free system to avoid potential hazards. The principle of cultural significance refers to the organic integration of pastoral culture, farming culture and community culture. Through the design, give the elderly community public space under the idyllic landscape with cultural and emotional, giving the elderly home experience. Presenting the pastoral landscape creates rich rural culture and community culture to arouse the countryside memories of the elderly, comfort their vulnerable psychology.

\section{B. The Design Principles of Picturesque Landscape}

Landscape culture is the soul of the ancient citye: with element of landscapement, through the means of literature and art, to reproducing the image of the beauteousness, pursuing the essence of beauty and the same artistic conception of poetry, and truly understanding the meaning and value of beings ${ }^{[2]}$."Mountains are cragged, in order to pave the way of the shape of landscape" - We have to be vibrated by the natural beauty of the magic of the landscape created by the nature itself. "Mountaineering fills mountains with emotion, viewing the sea the affection." The ancients learned from the habitude of landscapes, creating beautiful landscapes pictures, and expressing love of nature. The design principle of the 
beauty of landscape is precisely in such a thick cultural accumulation gradually established, as the old saying goes: "Mountain blocks wind. Mountain holds atmosphere. Water collects wealth. Place with mountain called auspicious. Place with water called hallowed.”

\section{The Design Principle of the Beauty of Poetry and Painting}

The same is true of poetry and painting: painting is physical poetry, poetry is intangible painting. Chinese poetry and painting culture has a long history. Song poet Su Dongpo's poem "Little Mausoleum invisible paintings, Han Dan painting without poem" reveals a "poetry containing painting, painting full of poem" dialectical thinking. The principle of the design of poetry and painting is to use the thoughts of "leaving the white, the artistic conception, the charm and the imagination" in poetry and painting, and to surpass the dull landscape reappearance by absorbing the thoughts of poetry and painting in the design. In landscape painting, the pursuit of endless resembling between idyllic landscape and traditional poetry and painting. For example, the Suzhou Museum is a very successful one "see the rockery" landscape, inspired by the landscape painting of MiFei, using the traditional Taihu stone to be the brush, the wall to be the baseboard. The mountain and lake match each other and full of vigor. Figure 1.

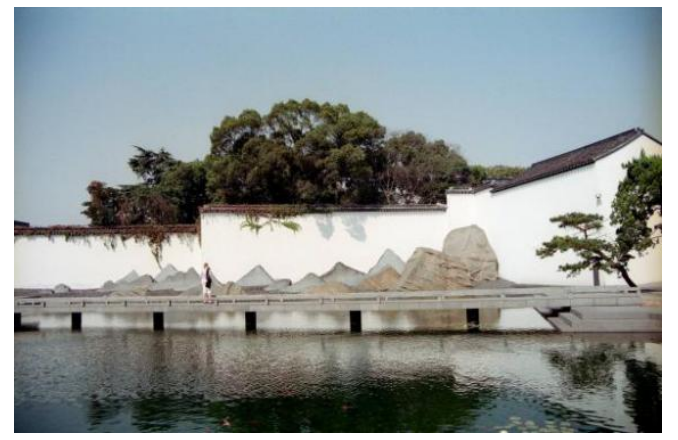

FIGURE I. SUZHOU MUSEUM FORGET ROCKERY

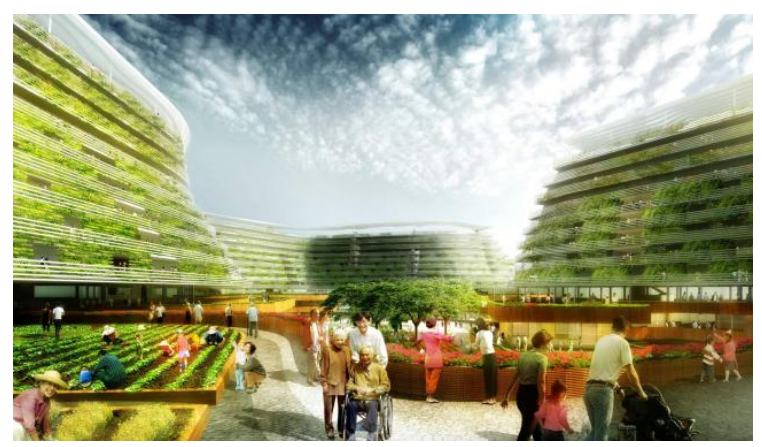

FIGURE II. SINGAPORE CITY MUSIC FARM RENDERINGS

\section{The Design Principle of Beauty of Pastoral}

The beauty of the garden lies in the elegance of the mountains and rivers, the simplicity of farmland gardens, the fragrance of grass and forests, and the richness of chickens, ducks and sheep. All these kinds of works are skillfully designed and deployed through the imaginative concept, so that the idyllic landscape design elements echo each other, and the concerted efforts finally converge to present the overall beauty. The design principle of incorporating the beauty of the pastoral into the design is to enable the elderly to enjoy the ecological life of the idyllic world and to create the idyllic landscape suitable for the elderly's physical and mental health so that the elderly may experience the fresh taste of the flowers and trees and thus enjoy the sensuality of nature.

\section{DESIGN CONCEPT OF PASTORAL LANDSCAPE DESIGN IN ELDERLy COMMUNITY PUBLIC SPACE}

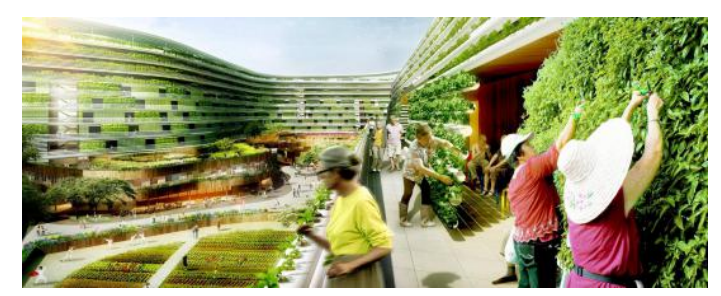

FIGURE III. SINGAPORE CITY MUSIC FARM RENDERINGS

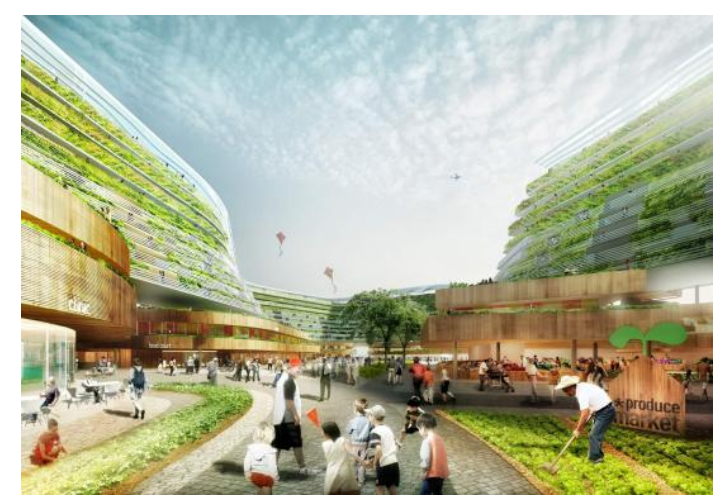

FIGURE IV.SINGAPORE CITY MUSIC FARM RENDERINGS

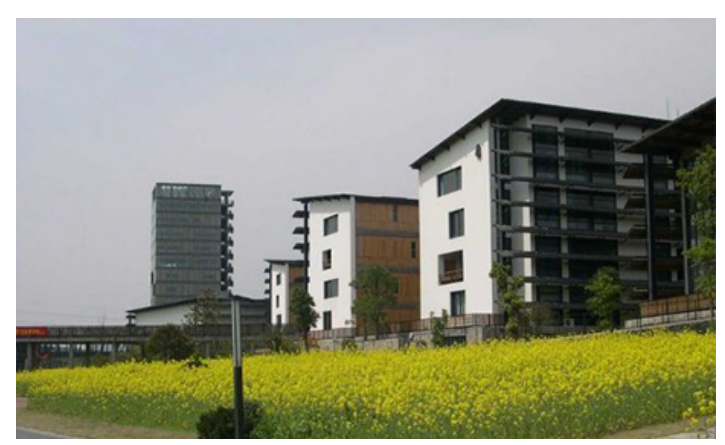

FIGURE V. RAPE FLOWER FIELD LANDSCAPE IN XIANG-SHAN

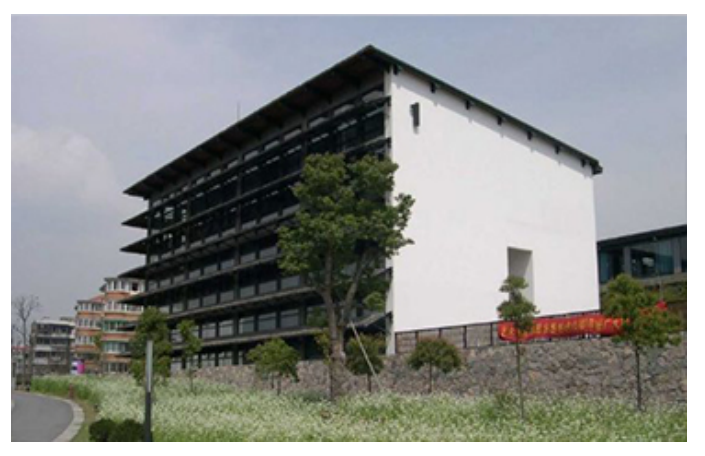

FIGURE VI.
WEEDS IN XIANG-SHAN CAMPUS 

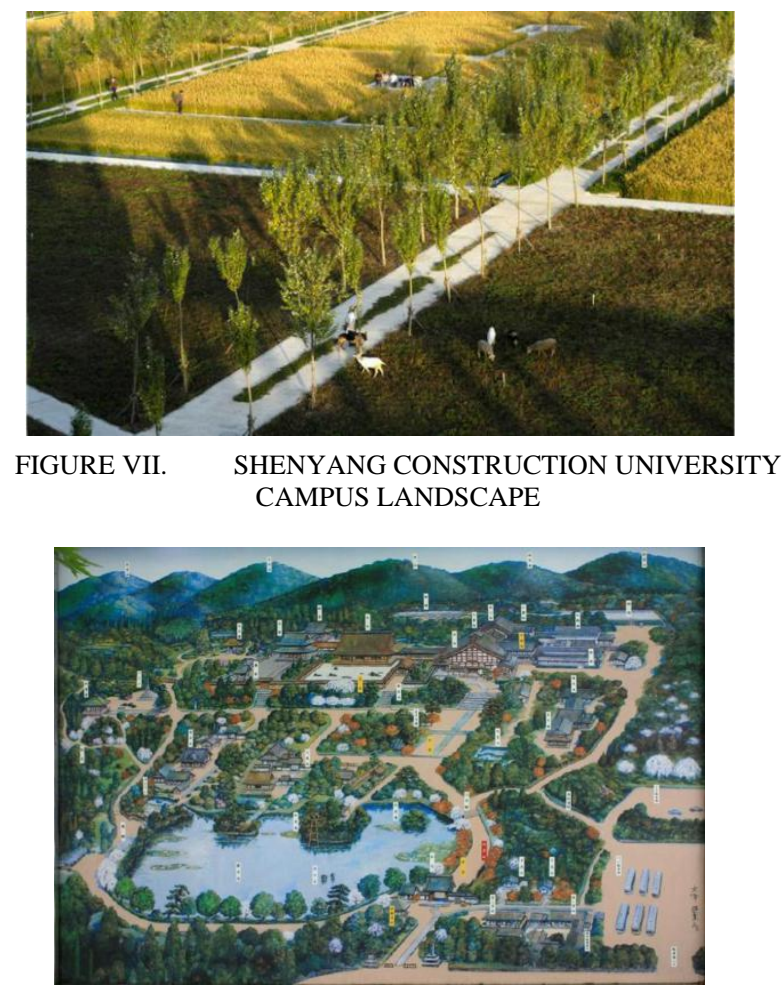

FIGURE VIII. JAPAN LONGAN TEMPLE PLAN

As early as 1798 , people realized that planting trees and flowers is good for people's health. From the theory of Kaplan's attention recovery, to the theory of Ulrich's stress recovery and the five-element rehabilitation garden proposed by Liu Binyi's scholars have explained. As the landscape design of recreational horticulture garden can comprehensively consider the auditory, olfactory and tactile decline of seniors, etc., the construction of pastoral landscape can be widely accepted and applied by using thermotherapy, hydrotherapy and horticultural therapy.

With the aging process of the elderly, their sense of smell becomes insensitive. Through gardening techniques, we cultivate the plants with heavy odors and healing features in garden scenery such as honeysuckle, mint, peony, ginkgo, dandelion, pipa, hawthorn, pine and cypress, plum blossom, sweet-scented osmanthus, monthly rose, as well as medicinal plants, to stimulate the sense of smell of the elderly to improve their olfactory function. Moreover, green plant in large scale was able to provide a refreshing aroma, adjuvant treatment of lung disease, bronchitis and respiratory diseases, to achieve the horticultural landscape recreational effect. In the auditory design through the establishment of horticultural rural waterfront landscape, the use of water sound, birds, dogs and other natural sounds can help to stimulate the elderly hearing, and to improve auditory function. Tactile design allows visually impaired seniors to feel humane care by touching and pressing, such as changing the texture on an unobstructed pavement and carving public facilities such as the arm rests and the back of the backrest in rural recreational spaces Braille or touch-sensing design allowing seniors to experience spatial changes.
Public space in the elderly community can also be designed. Through the horticultural plant technology, we can design rural landscape combined with the design of the outside world, unique, such as hyperthermia, hydrotherapy, horticulture and other idyllic garden sites. Hyperthermia is the use of the sun to kill bacteria while improving osteoporosis in the elderly. Hydrotherapy is the design of artificial hot springs, so that the elderly through the spa to clear the meridians, relieve stress and achieve comfort and calm effect. Horticultural therapy is the use of Cong planting and plantation and other landscaping landscaping practices, to create a return to nature pastoral landscape, to comfort patients and to transfer mental psychological emotions.

\section{A. Agricultural Pastoral Landscape Design}

There are three main ways to reproduce agricultural landscape design in the public community in the elderly community. The first is to reproduce the landscape design with the theme of flowers, fruits, vegetables and medicinal materials; the second is to reproduce the theme of the landscape design; and the third is to recreate the landscape design with the theme of the Four Seasons Garden.

Landscape design themed on flowers, fruits, vegetables and medicinal herbs is based on the aesthetics of gardening. For example, the urban residential buildings in Singapore are shown in Figures 2, 3 and 4, which are not only themed with flowers, fruits, vegetables and herbs Landscape design, but also in the balcony, roofs, corridors, aisles and plants planted to create the integration of landscape and architecture effect.The field landscape design is the design concept of abstract processing and reproduction of rural agricultural scenes through art design. For example, the rape field and the weed landscape of the China Academy of Art Xiangshan Campus designed by Wang Shu are shown in Figs. 5 and 6, and the agricultural landscape of Shenyang Construction University campus designed by Mr. Yu Kongjian of Peking University is shown in Fig. 7, which is a reproduction of the landscape design. Four seasons garden landscape design analyzes the seasonal growth of fruit trees, flowers and vegetables, including the flowering of fruit trees and flowers of various seasons, as well as the planting time of vegetables in various seasons, and then design the landscape with the changes in the season of agricultural countryside.

\section{B. China Ink and Wash Landscape Design}

Ink and wash painting often express the literator's landscape painting feelings through the rhythm of ink. Therefore, Qi Baishi, Wang Wei, Huang Gongwang, Wu Zhen and Ni Zan's landscape paintings are revealing love of natural landscapes. Through analyzing master pen painting, ink, color and composition, we can draw inspiration for pastoral landscape design. For example, in "Qingming Riverside", there is scattered composition and the four-position structure of Jing. Nothingness, blank convey the mood and reflect the essence of Chinese landscape painting. Application to the pastoral landscape design is pavilion, Pavilion, Xuan, Gallery, waterfalls, balconies and other elements freely embellished, but they can work together to create a healthy landscape of the elderly ink paintings. 
In the elderly community public space, building landscape paintings of Ink and Wash, the first is to be integrated with the environment, through clever design, so that the elderly get the immersive aesthetic experience. Second, through the use of ink and brush in the use of plane, layout and plant configuration, a landscape ink painting mood can be created. In Kyoto, Japan Longan Temple Classical Gardens, the layout is like an idyllic landscape ink paintings shown in Figure 8, which landscape design, not only contains the Zen mood, and plant configuration, orderly layout, clever layout, appropriate tactics.

\section{Rural Settlement Garden Landscape Design}

Rural settlement is a regional complex including towns, settlements, houses and temples with land ${ }^{[3]}$. The so-called settlement is a collective term for all kinds of places where human beings live, and is composed of various material elements such as buildings, structures, roads, green spaces and water sources. ${ }^{[4]}$ The public community in the elderly community should construct the landscape design not only to include the taste of local settlement, but also to include the rustic mood. Singapore Urban Bead Farmhouse has correspondingly considered the pastoral landscape design of the public community in the elderly (such ideas), combining production, pastoral and modern architecture to create a cosmopolitan-aged pension environment for the elderly to form a modern-style Pastoral landscape. However, because Singapore's urban aging farms can not reflect the national geographical features in architecture, this is where the limitations of their design lie. Therefore, I propose that the rural community public space in rural communities settle down idyllic landscape should be composed of two aspects of material composition and spiritual design.

First, the material composition includes landscapes of landscapes, pastoral scenery and the settlement patterns of native buildings. The public community in the elderly community should design the landscape architecture of the rural settlements, and should absorb the nutrition of local settlements such as centralized and scattered patterns of composition, drawing on traditional architectural usage of the colors of black, white, green, gray and other colors to refine and summarize the elegance and elegance of local architectural style elements and styles. It combines the landscaping elements of pastoral, peach, flowers and ponds with the essence of local settlement ideology and the idyllic landscape design philosophy unified coordination. Secondly, the spiritual composition includes customs, culture, neighborhood feelings, folk customs and production methods, and unifies the intangible culture of spiritual composition. Through the methods of reasoning and deduction, the artistic design techniques, should be combined. Organic combination of traditional rural settlement landscape can be built in place.

\section{V.CONCLUSION}

Old-style community public space idyllic landscape design as a new design concept has received the attention and attention to the design of contemporary rural landscape into a clear Qingquan. As the trend of population aging in our country continues to intensify, this coherent ancient and modern design concept of coordinating China and the West will continue to play a role. As for how to better promote the elderly community public space idyllic landscape design, technical operation remains to be further explored. This paper attempts to explore the application of pastoral landscape design in the public space of the elderly community, but there are still many limitations to my own knowledge and needs further study.

\section{REFERENCES}

[1] Elderly Livable Environment Blue Book: China's Disabled Elderly Population Over $\quad 40 \quad$ Million.2016-02-24. http://www.cssn.cn/zx/shwx/shhnew/201602/t20160224_2881532.shtml.

[2] LIU yan-ying .Study on the application of planning theory in landscape city -- a case study of Qianxi[D].Tian-jin University, 2013: 15-16.

[3] YU Kong-jian, WANG Zhi-fang, HUANG Guo-ping.On Local Landscape and its Significance to Modern Landscape Design[J].Hua-zhong Architecture, 2005(05): 123.

[4] ZHAO Jun-fen.Study on the Planning and Design of Rural Settlement Landscape in the West of Si-chuan Province -- a Case Study of Post Disaster Reconstruction in Mianzhu[D].Si-chuan Agricultural Uniersity.2009: 5-7. 